\title{
The Impacts of Social Security Expenditure on Rural Residents' Medical Consumption in Hubei Province
}

\author{
Yan Mengyu ${ }^{1}$ and Yang $\mathrm{Xi}^{1, *}$ \\ ${ }^{1}$ Hubei University of Chinese Medicine, Management School, 430065 Wuhan, China
}

\begin{abstract}
This paper analyzes the effect ofSocial Security Expenditure issued by Hubei Province on health services for the peasantry, and provides the evidences towards the integration process regarding medical insurances of the urban and the countryside.Based on the related economical data collected from countrysides area of Hubei province from 2003-2019, this paper utilizes the outcome of Cointegration and Granger Casual Relation Test to prove the relation from social security and employment fiscal expenditures and rural households' annual per capita net income.Then the research adds the control variables to perform the examination on robustness. The study shows that the social security expenditure has a significant impact on rural residents' medical consumption.Considering that medical insurance is an important part of social security,we should ensure the steadiness of the further improvement achieved by system of health insurance,increase government financial investment and strengthen the construction of rural basic health and medical facilities.Hubei Province should improve the level of rural medical and health security, strengthen management, improve efficiency and improve mechanisms, and deepen the reform of the medical and health system. Therefore, the economical burden of rural residents brought by seeking medical treatment will be reduced in order to narrow the difference between the urban and the countryside which will further promote the equality in medical system.
\end{abstract}

\section{Introduction}

In recent years, with the gradual advancement of medical and health system reform in China, from the new rural cooperative medical insurance system to the implementation of the basic medical insurance system for urban and rural residents, and then to the implementation of "Healthy China" as a national strategy, basic health care has achieved remarkable results.Among these, the basic medical security system plays a key role in the construction of medical and health undertakings. It is an important institutional arrangement.However, the current basic medical insurance system in China still has problems such as insufficient fairness, system division, and management division.Among them, the problems of the large gap between urban and rural areas and insufficient fairness have attracted much attention as a social hot spot.

According to data in the China Statistical Yearbook, China's total health expenditure in 2019 was 6584.139 billion yuan, and the proportion of total health expenditure in GDP increased from 3.96\% in 1990 to $6.64 \%$ in 2019 . It is worth noting that the proportion of rural health expenditures dropped from $47.02 \%$ to $23.49 \%$ during 1990-2016, and urban health expenditures increased from $52.98 \%$ to $76.51 \%$. The gap between urban and rural areas has been further widened, and the inequities in the health and medical field have become more and more serious. At the same time, various indicators reflecting the level of rural medical and health services, such as the proportion of rural health technicians in the national health technical personnel, the number of visits in hospitals, and the number of hospital beds in township hospitals per thousand population. These indicators all show a downward trend. Based on this, it is inferred that the situation of rural medical services are overall not optimistic, and the problem of dualization of urban and rural areas is severe.

From 2003 to 2019, residents' medical consumption expenditure data in Hubei Province and combined with the Comparison Chart of Urban and Rural Medical and Health Expenditure(Figure 1), in 2019, the annual per capita disposable income of rural households was $16,390.86$ yuan, and the annual per capita medical and health expenditure of rural households was 1,921.78 yuan, accounting for $12.54 \%$ of their consumption expenditures; the per capita disposable income of urban permanent residents is 37,601.36 yuan, and urban residents' medical and health expenditure is $2,471.35$ yuan, accounting for $9.35 \%$ of their consumption expenditure. Some scholars have shown that income level has a direct impact on medical expenditures. Moreover, in our country, the health of urban residents is higher than that of township residents, and there are health inequalities among the wealthy. Combined with the long-term economic constraints of rural residents in my country, the medical and health burden is heavier. These largely reflect the unfair social phenomenon

*Corresponding author: yangxi5762@aliyun.com 
brought about by the dualization of urban and rural areas in the field of social health and medical care.

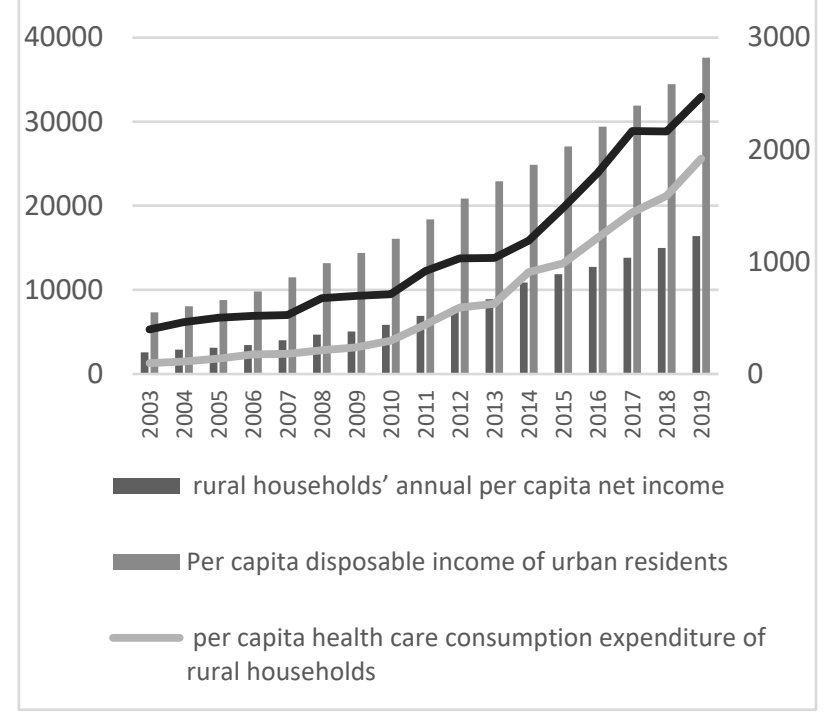

Fig.1. Urban and Rural Medical and Health Expenditure in Hubei Province (Unit: RMB Yuan).

Based on the above background, this article will start with the research on the medical consumption expenditure of rural residents in Hubei Province based on the data of the current situation in the rural areas of Hubei Province, and find the main influencing factors. This will reduce the burden of medical care for rural residents and help further narrow down the urban-rural gap in the field of medical and health care.

\section{Models, data and research methods}

\subsection{Theoretical model}

With the rapid development of all sectors of the economy and society, people's demands for utilization in the medical and health fields are also constantly increasing. Refer to the literature, the influencing factors for medical consumption expenditure are diverse.

First of all, the residents' income and the number of household laborers are important influencing factors. Xu Wei and Chen Huimei (2013) ${ }^{[1]}$ suggest that medical consumption expenditure of Chinese residents increases with the increase of income level, and the growth of rural residents' medical consumption is more sensitive to income. Tan Tao et al. (2014) ${ }^{[2]}$ find that family size and family income have a positive impact on medical consumption expenditure; household labor force and regional differences have a negative impact on it.

The second is that medical consumption expenditure is related to changes in social factors such as population aging and disease spectrum. The research results of Sun Qingchuan (2018) ${ }^{[3]}$ show that the aging of the population has a positive impact on the performance of medical consumption expenditure in the urban area, and the impact is growing rapidly.

It is generally believed that the intervention of the basic medical security system is a key role affecting expenditures in the field of health care. Shao Yanjia (2019) ${ }^{[4]}$ believes that the basic medical insurance has a significant impact on residents' medical consumption expenditures, and studied that its threshold effect in this context is significant among low-income groups. There are differences in the mechanism of basic medical insurance for low-, middle-, middle-high, and high-income groups.Huang Yuanfei and Zhang Jiaye (2017) ${ }^{[5]}$ and others believe that the medical burden of residents should be reduced,that is, medical consumption expenditures, we must start with the improvement of the basic medical insurance system. The differences in the implementation and formulation of different medical insurance systems have led to a large gap in the utilization of medical services among urban and rural residents in my country. Therefore, the integration of social basic medical insurance is of great significance in promoting the utilization of medical services, the level of social medical and health services, and improving social equity.

Based on the above argumentation, the medical security system is a very important link in the construction of rural basic health care. It is a necessary measure to reduce rural medical consumption expenditures and reduce the burden of medical care in rural areas. It is an important step in directly solving the problem of poor and expensive medical care in rural areas. Aiming at the research on the influencing factors of rural health and medical expenditure, this article takes the per capita medical and health expenditure of rural households as the research index.

The influencing factors are selected as follows: social security and employment fiscal expenditures, rural households' annual per capita net income, the number of rural medical setting spots, the number of rural doctors and health workers, and the number of rural junior high school graduates. In the empirical analysis, social security and employment fiscal expenditures are used as indicators to measure the medical insurance system for model analysis. The number of medical points set by the village is used as the index of rural medical service supply, and then the variables of the number of village doctors and health workers are added to test the robustness. The basic education level in rural areas is measured with the number of rural junior high school graduates as indicators, and variables such as farmers' disposable income are used as control variables in the model to accurately measure the impact of medical security inputs on rural medical consumption expenditures. It is hoped that through exploring the interaction between variables, it can provide a scientific reference for the Hubei government's rural health planning and the formulation and adjustment of medical insurance policies, and realize the realistic goal of rural revitalization. It has important reference significance for reducing the gap between urban and rural dualization.

Therefore, the factors that affect the per capita health care consumption expenditure of rural households (HCE) are selected as social security and employment fiscal expenditure (SEF), the number of rural junior high school graduates (RSG), rural households' annual per 
capita net income (RNI), and the number of ruralmedical setting spots(RMS).

To build the model as follows:

$$
\begin{array}{r}
\ln H C E_{t}=\beta_{1} \ln S E F_{t}+\beta_{2} \ln R S G_{t}+ \\
\beta_{3} \ln R N I_{t}+\beta_{4} \ln R M S_{t}+\varepsilon_{t}
\end{array}
$$

Among them, the indicator $\operatorname{lnHCE}_{t}$ reflects the growth rate of per capita medical and health consumption expenditure of rural households, $\varepsilon_{t}$ which is the residual item. The model setting is quite reasonable.

\subsection{Data Sources}

The sample data comes from the "Hubei Statistical Yearbook" (2004-2020). Since the pilot work of the new rural cooperative medical care system began in 2003 in China, this incident is of great significance to this research. Therefore, the year 2003 is chosen as the starting point for the analysis.

\subsection{Research Method}

The research first proceed the stationarity test, that is, to perform operating unit root tests on variables, and the most commonly used ADF test method is selected here. Determine the reasonable lag order of the model time series and ensure that the data is stable, and then use the EG two-step method to conduct a co-integration test to analyze whether there is a long-term equilibrium relationship between the variables. After that, Granger causality test is used to analyze whether there is a causal relationship between multiple variables, and to open a discussion. Finally, the robustness test was carried out by adding control variables to verify the impact of rural medical service supply on residents' medical consumption expenditure.

\section{Empirical results and analysis}

\subsection{Stationarity test}

The unit root test is performed on each variable to judge the stationarity of each variable time series. According to the Schwarz Info Criterion standard, the ADF is used to test the number of lags in the time series data. The results in Table 1 show that the original sequence of each variable failed the unit root test, indicating that the original sequence data and the first-order difference data are non-stationary.After that, the second-order difference of the variables is tested, and by observing the $\mathrm{P}$ value, all are less than 0.05 . This suggests that the second-order difference data of the variable is stationary. Therefore, it shows that the second-order difference of each variable is single integral, expressedas I(2). Then the cointegration test is performed on these variables.

\begin{tabular}{|c|c|c|c|c|c|c|}
\hline \multirow{2}{*}{ Variable } & \multirow{2}{*}{$\begin{array}{l}\text { ADF } \\
\text { value }\end{array}$} & \multicolumn{3}{|c|}{ Critical Value } & \multirow{2}{*}{$P$ value } & \multirow{2}{*}{ Conclusion } \\
\hline & & $1 \%$ & $5 \%$ & $10 \%$ & & \\
\hline $\operatorname{lnHCE}$ & -0.1558 & -3.9204 & -3.0656 & -2.6735 & 0.9266 & $\begin{array}{c}\text { non-station } \\
\text { ary }\end{array}$ \\
\hline $\mathrm{D}(\operatorname{lnHCE})$ & -4.5202 & -3.9591 & -3.0810 & -2.6813 & 0.0036 & stationary \\
\hline $\mathrm{D}(\operatorname{lnHCE}, 2)$ & -6.9665 & -4.0044 & -3.0989 & -2.6904 & 0.0001 & stationary \\
\hline $\operatorname{lnSEF}$ & 0.9685 & -2.7283 & -1.9663 & -1.6050 & 0.9062 & $\begin{array}{c}\text { non-station } \\
\text { ary }\end{array}$ \\
\hline $\mathrm{D}(\operatorname{lnSEF})$ & -5.5827 & -2.7719 & -1.9740 & -1.6029 & 0.0001 & stationary \\
\hline $\mathrm{D}(\operatorname{lnSEF}, 2)$ & -2.5317 & -2.7922 & -1.9777 & -1.6021 & 0.0168 & stationary \\
\hline $\operatorname{lnRNI}$ & -0.8565 & -3.9204 & -3.0656 & -2.6735 & 0.7746 & $\begin{array}{c}\text { non-station } \\
\text { ary }\end{array}$ \\
\hline $\mathrm{D}(\operatorname{lnRNI})$ & -2.9556 & -3.9591 & -3.0810 & -2.6813 & 0.0624 & $\begin{array}{c}\text { non-station } \\
\text { ary }\end{array}$ \\
\hline $\mathrm{D}(\operatorname{lnRNI}, 2)$ & -5.0655 & -4.0579 & -3.1199 & -2.7011 & 0.0019 & stationary \\
\hline $\ln R M S$ & 1.2540 & -4.8864 & -3.8290 & -3.3630 & 0.9997 & $\begin{array}{c}\text { non-station } \\
\text { ary }\end{array}$ \\
\hline $\mathrm{D}(\operatorname{lnRMS})$ & -10.1244 & -4.8864 & -3.8290 & -3.3630 & 0.0000 & stationary \\
\hline $\mathrm{D}(\operatorname{lnRMS}, 2)$ & -6.0112 & -4.99233 & -3.8753 & -3.3883 & 0.0026 & stationary \\
\hline $\operatorname{lnRSG}$ & -1.6813 & -3.9204 & -3.0656 & -2.6735 & 0.4211 & $\begin{array}{l}\text { non-station } \\
\text { ary }\end{array}$ \\
\hline $\mathrm{D}(\mathrm{InRSG})$ & -4.0019 & -3.9591 & -3.0810 & -2.6813 & 0.0092 & stationary \\
\hline D(lnRSG, 2) & -4.5020 & -4.0579 & -3.1199 & -2.7011 & 0.0047 & stationary \\
\hline
\end{tabular}

Table 1. Unit root test results.

\subsection{Cointegration test}

Considering that the period during which the sample was taken is 2003-2019 and the time series is not long, the Engle-Granger two-step method is used to explain the short-term dynamics. We regressed the independent variable and the dependent variable, and the results are shown in Table 2.

Table 2. Cointegration test results

\begin{tabular}{ccccc}
\hline $\begin{array}{c}\text { Variab } \\
\text { le }\end{array}$ & Coefficient & $\begin{array}{c}\text { Standard } \\
\text { deviation }\end{array}$ & Tvalue & Pvalue \\
\hline$C$ & $-15.8690 * * *$ & 3.1879 & -4.9779 & 0.0003 \\
lnSEF & $-0.3145^{* * *}$ & 0.0800 & -3.9183 & 0.0020 \\
lnRMS & $0.5369 *$ & 0.2811 & 1.9103 & 0.0803 \\
lnRSG & 0.0092 & 0.0477 & 0.1930 & 0.8502 \\
lnRNI & $2.0707 * * *$ & 0.1242 & 16.6680 & 0.0000 \\
\hline Notes: ******Significantat 10,5 and 1 percent levels, \\
respectively
\end{tabular}

Extract the estimated residual sequence RESID from the regression, and do a unit root test for the sequence.

Table 3. Result of Unit Root Test of Residual Sequence.

\begin{tabular}{ccccccc}
\hline \multirow{2}{*}{$\begin{array}{c}\text { Varia } \\
\text { ble }\end{array}$} & $\begin{array}{c}\text { ADFvalu } \\
\mathrm{e}\end{array}$ & \multicolumn{3}{c}{ Critical value } & Pvalue & $\begin{array}{c}\text { concl } \\
\text { usion }\end{array}$ \\
\cline { 3 - 6 } & & $1 \%$ & $5 \%$ & $10 \%$ & & \\
\hline $\begin{array}{c}\text { RESI } \\
\mathrm{D}\end{array}$ & -3.5124 & -3.9204 & -3.0656 & -2.6735 & 0.0218 & $\begin{array}{c}\text { statio } \\
\text { nary }\end{array}$ \\
\hline
\end{tabular}

It can be seen from Table 3 that the ADF test statistic is -3.5124 . Observing the $\mathrm{P}$ value, it can be considered that the estimated residual sequence RESID is a stationary sequence, and it is concluded that the sequences $\ln H C E, \operatorname{lnRSG}, \operatorname{lnRNI}$, InRMSand $\ln S E F$ have 
a co-integration relationship. The cointegration equation is obtained as follows:

$$
\begin{aligned}
\ln H C E_{\mathrm{t}} & =-15.8690+0.5369 \ln R M S_{t}+ \\
& 2.0707 \ln R N I_{t}+0.0092 \ln R S G_{t} \\
& -0.3145 \ln S E F_{t}
\end{aligned}
$$

From the equation, social security and employment fiscal expenditure (SEF) reflecting the supply of rural medical services are significantly negatively correlated with rural households' per capita medical and health consumption expenditure. Every increase of 1 unit in social security and employment fiscal expenditures will reduce therural households' annual per capita net incomeby 0.3145 units. The data shows that government social security fiscal expenditure has a greater impact on rural medical services, and the investment of social security funds has a significant impact on the implementation of medical treatment for rural residents. In the future, Hubei province should also continue to increase the level of social security protection and take it as the main force to control the medical and health expenditure of rural residents.

At the same time, it can also be observed that therural households' annual per capita net income and the per capita medical and health consumption expenditure of rural households show a significant positive correlation. For every increase in therural households' annual per capita net income by 1 unit, the rural residents' medical and health consumption expenditure will increase by 2.0707 units. Each increase in the number of ruralmedical setting spots will increase the consumption expenditure of rural residents by 0.5369 units; each increase in the number of rural junior high school graduates will increase the consumption expenditure of rural residents by 0.0092 units.

From the above, it can be seen that the two variables of social security and employment fiscal expenditures and therural households' annual per capita net income have relatively significant effects on health care consumption expenditures.

\subsection{Granger causality test}

According to the results of the above co-integration test, from 2003 to 2019, there is a long-term and stable equilibrium relationship between the social security and employment fiscal expenditures in Hubei Province, therural households' annual per capita net income, the Number of rural Medical setting spots, and the number of rural junior high school graduates. But whether it constitutes a short-term causality remains to be further verified. Therefore, Granger causality test is chosen to judge the short-term relationship between them. According to the AIC and SC information criteria, 2 lagging steps are selected. The results are shown in

\begin{tabular}{|c|c|c|c|}
\hline Null hypothesis & $\begin{array}{c}\text { F-Statisti } \\
\text { c }\end{array}$ & Prob. & Conclusion \\
\hline $\begin{array}{c}\text { LNHCE's } \\
\text { not LNRMS'sGranger reason }\end{array}$ & 0.6268 & 0.5541 & acceptance \\
\hline $\begin{array}{c}\text { LNRMS's } \\
\text { notLNHCE'sGranger reason }\end{array}$ & 0.1092 & 0.8976 & acceptance \\
\hline $\begin{array}{c}\text { LNHCE's } \\
\text { notLNRNI'sGranger reason }\end{array}$ & 0.2570 & 0.7784 & acceptance \\
\hline $\begin{array}{c}\text { LNRNI's } \\
\text { notLNHCE'sGranger reason }\end{array}$ & 2.4196 & 0.1390 & acceptance \\
\hline $\begin{array}{c}\text { LNHCE's not } \\
\text { LNRSG'sGranger reason }\end{array}$ & 13.262 & 0.0015 & $\begin{array}{l}\text { non- } \\
\text { acceptance }\end{array}$ \\
\hline $\begin{array}{c}\text { LNRSG's not } \\
\text { LNHCE'sGranger reason }\end{array}$ & 0.7095 & 0.5151 & acceptance \\
\hline $\begin{array}{c}\text { LNHCE's } \\
\text { notLNSEF'sGranger reason }\end{array}$ & 1.4385 & 0.2824 & acceptance \\
\hline $\begin{array}{c}\text { LNSEF's } \\
\text { notLNHCE'sGranger reason }\end{array}$ & 2.3533 & 0.1454 & acceptance \\
\hline $\begin{array}{c}\text { LNRMS's not } \\
\text { LNRNI'sGranger reason }\end{array}$ & 3.6367 & 0.0650 & $\begin{array}{c}\text { non- } \\
\text { acceptance }\end{array}$ \\
\hline $\begin{array}{l}\text { LNRNI's not } \\
\text { LNRMS'sGranger reason }\end{array}$ & 0.2667 & 0.7712 & acceptance \\
\hline $\begin{array}{c}\text { LNRMS's not } \\
\text { LNRSG'sGranger reason }\end{array}$ & 1.6141 & 0.2469 & acceptance \\
\hline $\begin{array}{c}\text { LNRSG's } \\
\text { notLNRMS'sGranger reason }\end{array}$ & 0.1691 & 0.8468 & acceptance \\
\hline $\begin{array}{c}\text { LNRMS's } \\
\text { notLNSEF'sGranger reason }\end{array}$ & 5.6298 & 0.0230 & $\begin{array}{l}\text { non- } \\
\text { acceptance }\end{array}$ \\
\hline $\begin{array}{c}\text { LNSEF's } \\
\text { notLNRMS'sGranger reason }\end{array}$ & 4.9077 & 0.0327 & $\begin{array}{l}\text { non- } \\
\text { acceptance }\end{array}$ \\
\hline $\begin{array}{c}\text { LNRNI's } \\
\text { notLNRSG'sGranger reason }\end{array}$ & 3.9864 & 0.0533 & $\begin{array}{c}\text { non- } \\
\text { acceptance }\end{array}$ \\
\hline $\begin{array}{c}\text { LNRSG's } \\
\text { notLNRNI'sGranger reason }\end{array}$ & 2.3986 & 0.1410 & acceptance \\
\hline $\begin{array}{c}\text { LNRNI's } \\
\text { notLNSEF'sGranger reason }\end{array}$ & 0.4215 & 0.6672 & acceptance \\
\hline $\begin{array}{c}\text { LNSEF's not } \\
\text { LNRNI'sGranger reason }\end{array}$ & 1.3669 & 0.2987 & acceptance \\
\hline $\begin{array}{c}\text { LNRSG's } \\
\text { notLNSEF'sGranger reason }\end{array}$ & 2.0274 & 0.1823 & acceptance \\
\hline $\begin{array}{c}\text { LNSEF's } \\
\text { notLNRSG'sGranger reason }\end{array}$ & 0.0512 & 0.9503 & acceptance \\
\hline
\end{tabular}
Table 4.
Table 4. Granger causality test.

It is worth noting from the test results of the above table that social security and employment fiscal expenditures are the reasons for the increase in the number of rural medical setting spots, which is consistent with the research conclusions and social laws in some existing related documents. For rural areas with relatively backward economic development and slower growth rates, the government can directly increase the supply of medical and health services by increasing social security investment, thereby reducing overall medical consumption expenditures in rural areas and achieving the effect of narrowing the gap between urban and rural areas. Reduce the negative impact of the dual structure of urban and rural areas.

\section{Robustness test}

In order to further verify the accuracy of the model, in addition to the core explanatory variables to be investigated, based on the combing of existing data and analysis of the current situation, variables such as the 
number of rural doctors and health workers (RHW) are added as control variables. Perform the inspection according to the above steps, and the results are shown in Table 5 below.

Table 5.Robustness test results

\begin{tabular}{ccccc}
\hline Variable & Coefficient & $\begin{array}{c}\text { Standard } \\
\text { deviation }\end{array}$ & Tvalue & Pvalue \\
\hline$C$ & $-16.2748^{* * *}$ & 3.4506 & -4.7165 & 0.0006 \\
$\operatorname{lnRHW}$ & -0.1170 & 0.2863 & -0.4087 & 0.6906 \\
$\operatorname{lnRMS}$ & 0.7181 & 0.5306 & 1.3536 & 0.2030 \\
$\operatorname{lnRNI}$ & $2.0605^{* * *}$ & 0.1312 & 15.7061 & 0.0000 \\
$\operatorname{lnRSG}$ & -0.0030 & 0.0517 & 0.0578 & 0.9549 \\
$\operatorname{lnSEF}$ & $-0.3153^{* * *}$ & 0.0831 & -3.7961 & 0.0030 \\
\hline \multicolumn{4}{l}{ Notes: ***Significant at 1 percent level }
\end{tabular}

The results in Table 5 show that after adding a set of control variables, among several sets of explanatory variables, social security and employment fiscal expenditures (SEF) reflecting rural medical service supply are still significantly negatively correlated with rural households' per capita health care consumption expenditures. Its coefficient is -0.3153 , and therural households' annual per capita net income is also have a significant effect on rural residents' medical and health consumption expenditures. At the same time, the regression coefficient values of other control variables change very little, which shows that the research conclusion has not changed substantially when the number of control variables changes. An empirical conclusion can be drawn: social security and employment fiscal expenditures (SEF) have significant negative effects with rural households' per capita health care consumption expenditures.

\section{Conclusion}

Through the analysis of rural medical consumption expenditure in Hubei Province, the following research conclusions are mainly formed:

Social security and employment fiscal expenditures (SEF) have significant negative effects with rural households' per capita medical and health consumption expenditures (HCE), and there is a long-term equilibrium relationship between the two variable.It can be seen that the investment in social security fiscal expenditure has a significant impact on rural medical consumption expenditure. The per capita disposable income of rural residents has the greatest impact on health care expenditures.

Rural medical consumption expenditure as an indicator can reflect to a large extent the level of rural medical and health services. Therefore, it is speculated that social security investment is also one of the important factors affecting the improvement of rural medical and health services.

Since the data on social medical insurance funds is difficult to obtain and considering that social medical insurance is an important part of our country's social security system, the above conclusions can be used to infer the logical relationship between social medical insurance and rural medical consumption. Therefore, the following suggestions can be made in the field of medical security. The intention is to analyze the reform of Hubei medical security and the health sector through the impact of social security investment on rural medical consumption expenditure, complete the anti-poverty role of the medical security system, and indirectly reduce the unfair social phenomenon in Hubei brought about by the dual structure of urban and rural areas.

First, HubeiProvince shouldaccelerate the construction of urban-rural integration of medical insurance, and comprehensively improve the basic medical insurance system for urban and rural residents.

In the research of Qiu Yulin and Wang Zhaoqian scholars, it is clearly pointed out that the actual integration process of the urban and rural medical insurance system lags behind the expected plan, and there are both explicit fairness and implicit unfairness ${ }^{[6]}$.Meng Yingying scholar emphasized that equity is an important factor in the sustainable development of the social security system ${ }^{[7]}$. Therefore, when further narrowing the gap between urban and rural areas, we should pay special attention to equity and gradually determine the perfection and improvement of the basic medical insurance system for urban and rural residents.

Second, the relevant national departments shoulddeepen the reform of county-level hospitals, and solve the difficult and expensive problems in the medical field

At present, the rural population still faces the reality that access to medical care is difficult and expensive in Hubei Province. After referencing the research of Huang Dayong and other scholars on the medical reform measures of county-level hospitals ${ }^{[8]}$. In order to reduce the waste of medical resources and expand the accessibility of basic medical and health services, This article suggeststhe reform of county-level public hospitals should be initiated in Hubei province.It helps to effectively promote the implementation of graded diagnosis and treatment. By further improving medical insurance and clarifying the medical insurance catalogue, the problem of expensive medical care can be solved. The construction of community hospitals in towns and townships and the improvement of the level of primary medical care were carried out to solve the problem of difficult medical care.

Third, The National Medical Security Administration need to focus on accurate identification and comprehensive coverage.

At present "sicknesspoor" and "poverty due to illnes $s "$ problem are huge obstacles on the road to povert $y$ alleviation in our country. In the context of rural revitalization and poverty alleviation, we can start fr om the perspective of improving the medical insuran ce system, so that the basic medical insurance syste $\mathrm{m}$ can achieve accurate coverage, and the phenomen on of duplicate insurance in the cohabitation data ca $\mathrm{n}$ be eliminated. Promote the narrowing of the urba n-rural gap from the side. 
Finally, this article will conduct policy analysis for the post-epidemic era.

Since the emergence of the new coronavirus epidemic is relatively short, the accumulated data is not enough to support specific research. Therefore, by combining social phenomena, exposed issues in the health and medical field, and related policies, suggestions are made for the construction of urban and rural medical and health services in the post-epidemic era.

Although our country's public health service system was generally effective when it first responded to the new coronavirus epidemic, there were still some weaker links. Therefore, great attention should be drawn to the construction of the medical and health field in the overall situation. In the post-epidemic period, our government should continue to build a strong public health system and build a clear medical and health network. Among them, accelerating the establishment of an urban-rural community linkage working mechanism is an indispensable plan for improving the public health system and building a medical and health defense network.

The shortcomings of rural epidemic prevention have been exposed, and rural medical and health work is still the top priority of epidemic prevention and control. At present, the basic capacity of rural health and epidemic prevention is weak, and residents' awareness of disease prevention is relatively insufficient. It is particularly important to strengthen the linkage management of primary medical and health institutions. Strictly follow the triage system to exchange information control in a timely manner is the ideal situation we expect. This reflects the importance and urgency of the construction of the primary medical and health network in rural construction. In summary, forming a working mechanism for urban-rural community linkage as soon as possible can not only speed up the completion of our country's public health shortcomings and improve the safety factor of social public health, but also further promote urban-rural linkages and mobility. It is conducive to breaking the dual barriers between urban and rural areas, effectively reducing the difference between urban and rural areas in the medical and health and social fields, and creating a harmonious and fair social atmosphere.

\section{References}

1. Xu Wei, Chen Huimei.Influence of income on resident medical consumption expenditure in China [J]. China Health Policy Research. 2013,6(06):52-57.

2. Tan Tao, Zhang Yanyuan, He Jun.An Analysis of Influencing Factors and Elasticity of Rural Households' Medical Consumption Spending in China[J]. Journal of Shanghai University of Finance and Economics: Philosophy and Social Sciences Edition, 2014.
3. Sun Qingchuan. Empirical Analysis of the Influence of Population Aging on Medical Expenditure[D]. Beijing Technology and Business University.2018.

4. Shao Yanjia. Research on the Threshold Effect of China's Basic Medical Insurance on Residents' Medical Consumption Expenditure[D]. Southwest University for Nationalities.2019.

5. Huang Yuanfei, Zhang Jiaye. The impact of the integration of urban and rural medical insurance on the utilization of rural residents' medical services: Taking Guangzhou as an example[J]. China Public Policy Review, 2017, (01):34-52.

6. Qiu Yulin, Wang Zhaoqian, Qiu, et al. The Evaluation and Analysis of Integrating Urban and Rural Residents Basic Medical Insurance System[J]. China Medical Insurance, 2018, 02(113): 20-24.

7. Meng Yingying. Reform and Transition:The Practice of the Fair and Sustainable Development for the Social Security System in China[J]. Social Security Research, 2014, (06):62-68.

8. Huang Dayong, Yuan Jun, Hu Changyong. Research on the operation and social benefit evaluation of county-level public hospitals by the five major medical reform measures[J]. Chongqing Medicine, 2019,48(16): 2870-2872. 